\title{
TESTOSTERONE-INDUCED, SULFONAMIDE-RESISTANT CARBONIC ANHYDRASE ISOZYME OF RAT LIVER IS INDISTINGUISHABLE FROM SKELETAL MUSCLE CARBONIC ANHYDRASE III
}

\author{
Nicholas D. CARTER, David HEWETT-EMMETT ${ }^{+}$, Stephen JEFFREY and Richard E. TASHIAN ${ }^{+}$ \\ Department of Child Health, St George's Hospital Medical School, London, SWI 7 ORE, England and ${ }^{+}$Department of Human \\ Genetics, University of Michigan Medical School, Ann Arbor, MI 48109, USA
}

Received 14 April 1981

\section{Introduction}

Three isozymes of carbonic anhydrase, CA I, CA II and CA III, have been characterized from the tissues of a variety of vertebrate species. CA I (low-activity, sulfonamide-sensitive form) has been found mainly in red cells but also occurs in other tissues (e.g., rumen epithelium, caecum, colonic mucosa, pituitary gland, ciliary body), CA II (high-activity, sulfonamide-sensitive form) is found in red blood cells and in a majority of other tissues, and CA III (low-activity, sulfonamideresistant form) has been reported to occur largely in red skeletal muscle; cf. [1-7]. Although all 3 isozymes catalyze the reversible hydration of $\mathrm{CO}_{2}$, hydrolyze certain ester linkages, and are selectively inhibited by heterocyclic sulfonamides such as acetazolamide (Diamox), their relative activities and degrees of sulfonamide inhibition can vary considerably. For example, the CA II isozymes have the highest $\mathrm{CO}_{2}$ hydrase and esterase (toward $p$-nitrophenyl acetate) activities and the highest affinities for sulfonamides, followed by the CA I isozymes, while the CA III isozymes exhibit markedly lower $\mathrm{CO}_{2}$ hydrase and esterase activities and are only weakly inhibited by sulfonamides [1-4].

Early studies on carbonic anhydrase activity in rat liver homogenates [8,9] showed that its $\mathrm{CO}_{2}$ hydrase activity was poorly inhibited by acetazolamide compared to the strong inhibition of rat red cell carbonic anhydrase (presumably CA I and CA II) activities. A partial characterization of a carbonic anhydrase isolated from livers of adult male rats [10] showed that the specific $\mathrm{CO}_{2}$ hydrase activity of this form was $\sim 1 \%$ that of the high-activity CA II isozyme purified from rat red cells, and that it was $\sim 10000$-times less sensitive to inhibition by acetazolamide. The production of rat liver carbonic anhydrase, separated from CA II, could be specifically induced by testosterone [11].

From these immunodiffusion, electrophoretic and amino acid sequence studies, the sulfonamide-resistant carbonic anhydrase of the male rat liver appears identical or very closely related to the major carbonic anhydrase isozyme, CA III, of rat skeletal muscle. This rat liver CA III should prove to be a valuable marker for studies on the hormonal control of mammalian gene expression.

\section{Materials and methods}

\subsection{Purification of carbonic anhydrase isozymes}

The rat CA I and CA II isozymes were purified from rat hemolysates by affinity chromatography on sulfonamide (Prontosil) columns as in [12]. The putative CA III isozymes were initially prepared from rat skeletal muscle and liver homogenates by affinity chromatography [12] on similar columns equilibrated with $0.01 \mathrm{M}$ Tris $-\mathrm{SO}_{4}(\mathrm{pH} 8.7)$ and eluted with a $0-0.4 \mathrm{M}$ KI gradient. Further purification was carried out on DEAE-32 cellulose columns equilibrated with $0.01 \mathrm{M}$ Tris $-\mathrm{HCl}$ buffer $(\mathrm{pH} \mathrm{8.7)}$ and eluted with a $0-0.2 \mathrm{M}$ $\mathrm{NaCl}$ gradient. Subsequent purification of the CA III isozymes was carried out by passage through a Sephadex G-75 column equilibrated with $0.005 \mathrm{M}$ Tris- $\mathrm{HCl}$ buffer ( $\mathrm{pH}$ 8.0). All stages of purification for the CA III isozymes contained $0.5 \mathrm{mM}$ dithiothreitol, as CA III from human and rabbit muscle is known to dimerize $[3,6]$. 


\subsection{Acetazolamide inhibition}

The $I_{50}$-values for acetazolamide were determined on the carbonic anhydrase activity in the supernatant fractions of crude liver and muscle homogenates. The $\mathrm{CO}_{2}$ hydrase activity were measured using the bromothymol blue assay, after correction for CA I and CA II contamination [6].

\subsection{Immunological procedures}

Ouchterlony, double immunodiffusion plates were prepared by the standard methods. Antisera raised in New Zealand White rabbits to bovine CA III and rat CA I and CA II were prepared by subcutaneous injections of a mixture containing $1 \mathrm{mg}$ purified antigen in $0.8 \mathrm{ml}$ physiological saline $(0.85 \%)$ and $0.8 \mathrm{ml}$ Freund's complete adjuvant. The same procedure (with Freund's incomplete adjuvant) was followed 3 weeks later, with additional injections at weekly intervals for the following 2 weeks. The rabbits were bled 1 week after the last injection, and the serum harvested.

\subsection{Electrophoresis and isoelectric focusing}

Flectrophoresis was carried out for $2 \mathrm{~h}$ at $350 \mathrm{~V}$. on cellulose acetate gels (Cellogel) at pH $9.1(0.09 \dot{\mathrm{M}}$ Tris, $0.003 \mathrm{M}$ EDTA, $0.01 \mathrm{M}$ boric acid). The carbonic anhydrase bands were then located by their $\mathrm{CO}_{2}$ hydrase activity with the bromothymol blue method [13], and stained for protein with a $0.3 \%$ solution of Coomassie brilliant blue. Slab SDS-polyacrylamide gel electrophoresis (12.5\% separating gel, 5\% stacking gel) was done essentially as in [14]. For the isoelectric focusing in polyacrylamide gel, $75 \mu \mathrm{g}$ purified samples of the carbonic anhydrase isozymes were applied to an LKB Ampholine PAG plate (pH 5.5-8.5), and run for $2.5 \mathrm{~h}$ at $10^{\circ} \mathrm{C}$.

\subsection{Amino acid sequence analysis}

The sequencing procedures employed were essentially as in $[13,15]$. The desalted, lyophilized carbonic anhydrase isozymes from liver and muscle were cleaved using cyanogen bromide in $70 \%$ formic acid. The cleaved fragments were then separated by gel filtration on Sephadex G-75 in 10\% acetic acid, and the lyophilized peaks were subjected to automated sequencing. The PTH-amino acids were identified by isocratic high performance liquid chromatography [13], or, in the case of PTH-Arg, by a spot test [15].

\section{Results}

\subsection{Electrophoretic identity}

As seen in fig. 1, the electrophoretic mobilities in cellulose acetate of the purified rat liver and rat muscle carbonic anhydrases are identical but different from both CA I and CA II. Of the 4 forms, CA II most readily generates secondary bands. The molecular masses of the liver and muscle carbonic anhydrases also appear to be identical based on their similar migration patterns in SDS-polyacrylamide gel electrophoresis (fig.2).

The sulfonamide resistance of the liver and muscle isozymes could be readily demonstrated in that the activities of the red cell CA I and CA II isozymes (after cellulose ace tate electrophoresis) were completely inhibited by treatment with $10^{-4} \mathrm{M}$ acetazolamide,

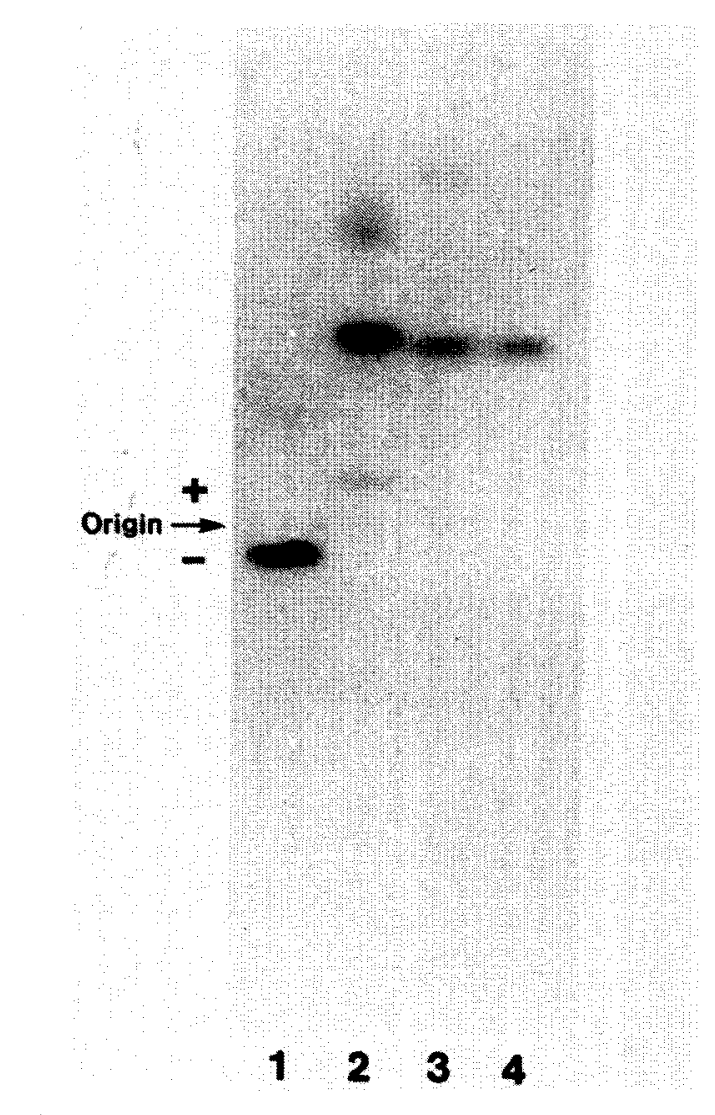

Fig.1. Electrophoretic patterns of CA I and CA II purified from rat ery throcy tes and CA III purified from rat liver and skeletal muscle: (1) CA I; (2) CA II; (3) muscle CA III; (4) liver CA III. Electrophoresis done in cellulose acetate (pH 9.1). See text for details. 


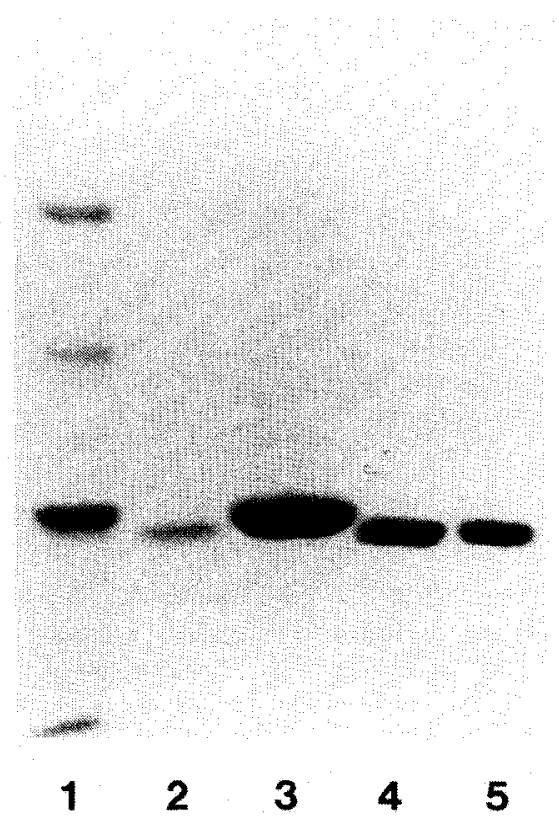

Fig.2. SDS-polyacrylamide gel electrophoresis of CA I and CA II purified from rat ery throcytes and CA III purified from rat liver and skeletal muscle: (1) $M_{\mathrm{r}}$ markers $\left(\times 10^{-3}\right.$, from top) - bovine serum albumin (66), ovalbumin (45), human CA II (29) and bovine RNase (14); (2) CA I; (3) CA II; (4) muscle CA III; (5) liver CA III. See text for details.

whereas the $\mathrm{CO}_{2}$ hydrase activities of the liver and muscle enzymes still retained considerable activity in the presence of this concentration of the sulfonamide.

The isoelectric focusing experiment (not shown) revealed that the CA I, CA II, liver and muscle isozymes had similar mobilities. Once again, CA II, pure as judged by SDS-polyacrylamide gel electrophoresis, gave multiple bands on isoelectric focusing gels.

\subsection{Inhibition identity}

$I_{50^{-v}}$ values of $\sim 10^{-4} \mathrm{M}$ were consistently obtained for the inhibition of carbonic anhydrase activity with acetazolamide in rat liver and muscle extracts, in general agreement with $I_{50}$-values (acetazolamide) obtained for CA III purified from rabbit and ox muscle $[4,16]$.

\subsection{Immunological identity}

The immunodiffusion patterns of the liver and muscle carbonic anhydrase isozymes were identical to each other and to human muscle CA III, and showed a line of identity (with spurring) to bovine CA III (fig.3). The rat red cell CA I and CA II isozymes did not cross-react with rabbit anti-bovine CA III sera. Precipitation bands with rabbit anti-rat CA II sera were observed only with rat CA II, and cross-reaction with rabbit anti-rat CA I sera was seen only with rat CA I.

\subsection{Amino acid sequence identity}

Homologous cyanogen bromide fragments from rat liver and muscle carbonic anhydrases were partially sequenced and found to be identical (table 1). The 15 residues in this sequence (representing positions 79 92) were also found to be highly homologous with sequences of CA III isolated from human, gorilla and
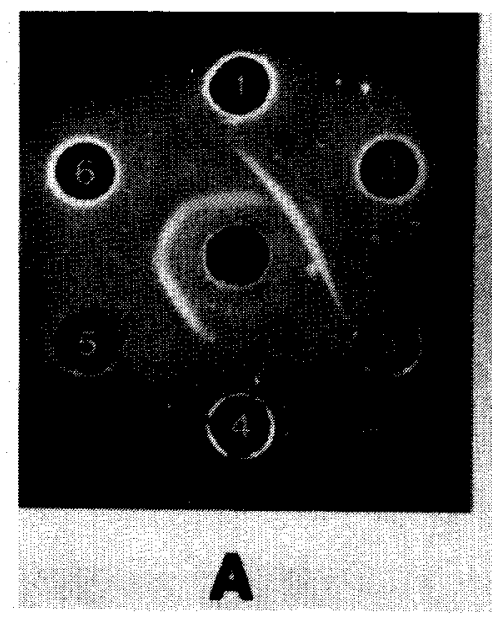

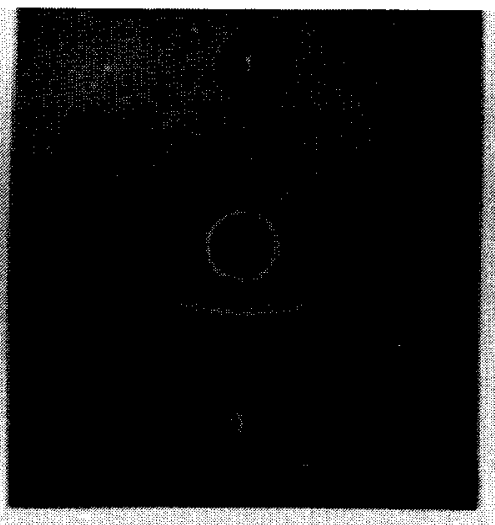

B
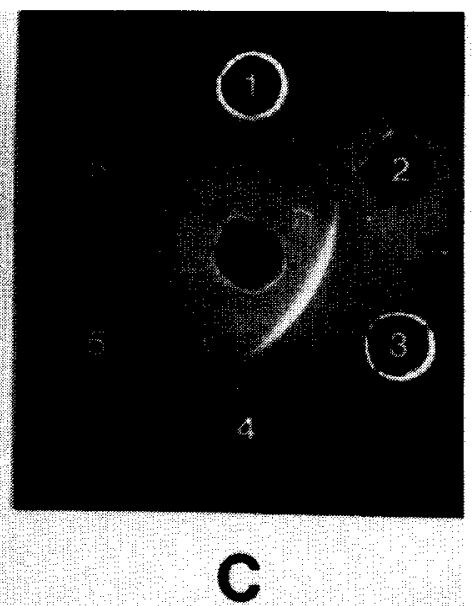

Fig.3. Double immunodiffusion patterns of antiserum against bovine CA III (center well, A), rat CA II (center well, B) and rat CA I (center well, C). Outer wells: (1) human muscle CA III; (2) bovine muscle CA III; (3) rat red cell CA II; (4) rat red cell CA I; (5) rat liver CA III; (6) rat muscle CA III. See text for details. 
Table 1

Amino acid sequences of cyanogen bromide fragments from rat liver and muscle carbonic anhydrases aligned with homologous sequences of other mammalian carbonic anhydrase isozymes

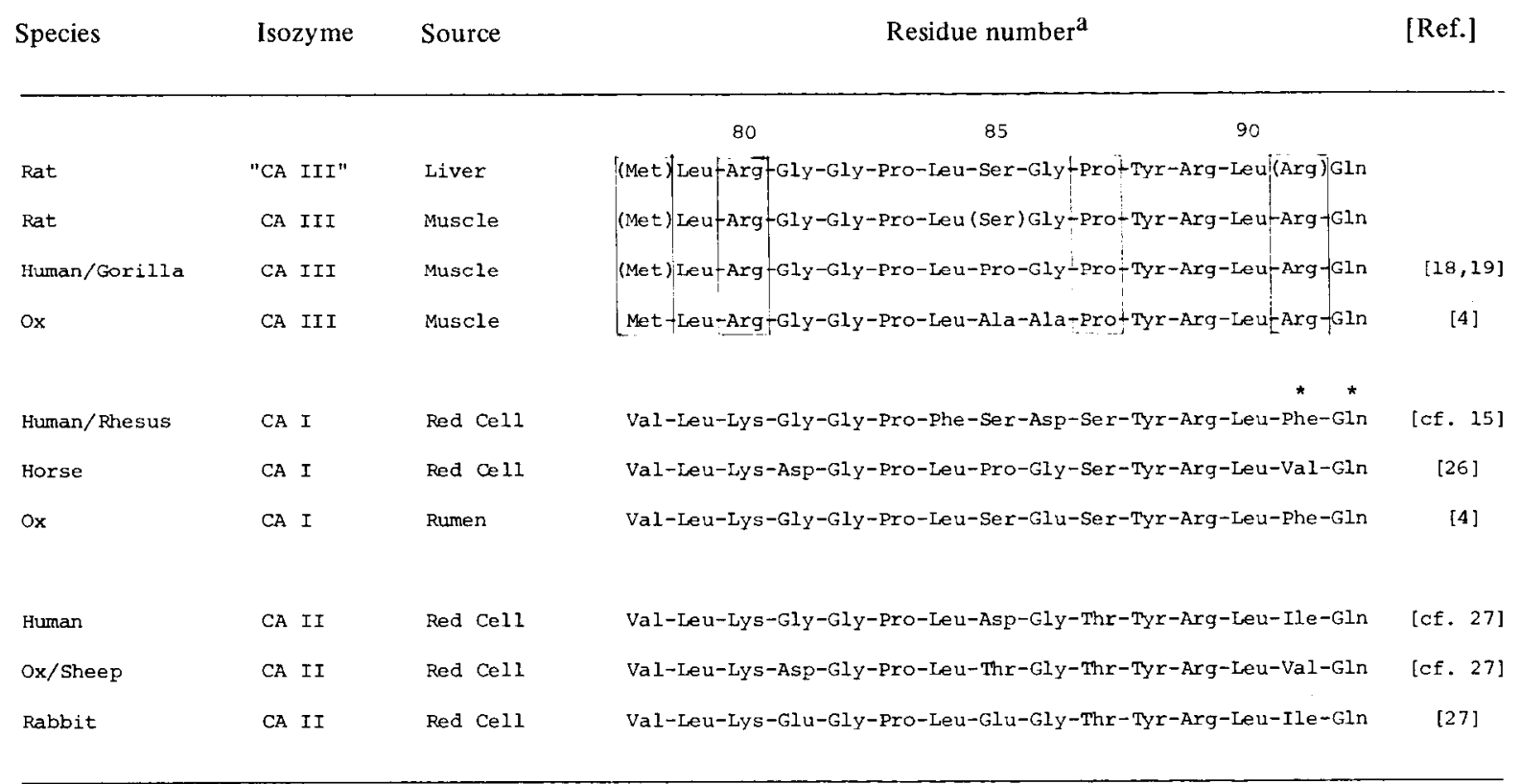

a Based on human CA I numbering; cf. [4]

* Residues located in the active sites of human CA I and CA II cf. [4]

Residucs in boxes appear to be unique to CA III isozymes

ox skeletal muscle, and shared residues at 4 positions (78-Met, 87-Pro, 80-Arg and 91-Arg) which appear to be unique to the CA III isozymes. Thus, the rat liver and muscle isozymes are clearly more homologous to other CA III isozymes than to the CA I and CA II isozymes.

\section{Discussion}

Because relatively high levels (i.e., $1-2 \%$ wet muscle wt) of a low-activity, sulfonamide-resistant carbonic anhydrase isozyme has been reported from the skeletal muscle of chicken [2], cat [2], sheep [2], ox [4], rabbit $[3,16]$, mouse [17], human $[6,18]$ and gorilla [19], it has been generally believed that these isozymes are all homologous forms of an isozyme, designated CA III, that are essentially confined to skeletal muscle. Nevertheless, trace amounts of CA III have also been detected immunologically from sheep lung [17], rabbit liver [17], and human liver, smooth muscle, lung, and cardiac muscle [20].
It now appears that high levels of CA III which is structurally indistinguishable from rat muscle CA III is also normally present in mature male rat liver. Utilizing an electrophoretic immunoassay [20,21], it was estimated that the concentration of CA III in adult male rat livers was $\sim 2.5$-times that found in rat skele tal muscle, i.e., $\sim 5 \%$ of the soluble liver protein and $2 \%$ of the soluble muscle protcin was CA III. Interestingly, this isozyme can be induced by testosterone since it is reduced in the livers of castrated rats, and increased in livers of female rats (where it is normally absent) by testosterone treatment [11]. Furthermore, it appears that the high-activity, sulfonamidesensitive CA II isozyme can be induced by estrogen in the livers of both male and female rats [22]. It thus seems that normally the main adult rat liver isozyme is CA II in the female and CA III in the male.

Although our results suggest that the CA III isozymes of rat liver and skeletal muscle are the products of the same gene, this can only be resolved when additional structural and genetic evidence is obtained. 
For example, in humans 2 closely-linked genes code $\alpha$-globins of identical amino acid sequence and 2 closely-linked genes code $\gamma$-globins which differ by only an electrophoretically silent Ala/Gly interconversion; cr. [23]. Clearly, even complete sequencing does not always indicate the presence of 2 gene loci.

Other rodent liver proteins, rat $\alpha_{2 \mathrm{u}}$-globulin and mouse major urinary proteins (MUP's), are known to be inducible by testosterone; cf. [24]. Rat $\alpha_{2 u}$-globulin is similar to rat liver CA III in that it is normally synthesized in adult male rats and absent in female rats. In contrast, MUP's (which may be evolu tionarily related to $\alpha_{2 u^{-g}}$ globulin) are excreted by both adult male and female mice, although males excrete higher levels. In this respect, it is of interest that both adult male and female mice appear to exhibit similar levels of CA III in their livers [2].

The finding [25] that a sulfonamide-sensitive form of carbonic anhydrase is present in guinea pig liver and skeletal muscle mitochondria, but absent from heart, brain and kidney mitochondria, is noteworthy because it appears to parallel the distribution of rat CA III reported here.

\section{Acknowledgements}

We acknowledge the expert assistance of Ya-Shiou L. Yu, Jane Batten and Sarah Moyle in isozyme purification and analysis, Patrick J. Venta in preparing antisera, and R. Scott Decker in the isoelectric focusing experiments. Supported in part by USPHS grant GM-24681.

\section{References}

[1] Tashian, R. E. (1977) in: Isozymes: Current Topics in Biological and Medical Research (Rattazzi, M. C. et al. eds) vol. 2, pp. 21-64, Alan R. Liss, New York.

[2] Holmes, R. S. (1977) Eur. J. Biochem. 78, 511-520.

[3] Register, A. M., Koester, M. K. and Noltmann, E. A. (1978) J. Biol. Chem. 253, 4143-4152.
[4] Tashian, R. E., Hewett-Emmett, D., Stroup, S. K., Goodman, M. and Yu, Y.-S. L. (1980) in: Biophysics and Physiology of Carbon Dioxide (Bauer, C., Gros, G. and Bartels, H. eds) pp. 164-176, Springer-Verlag, Berlin, Heidelberg, New York.

[5] Tashian, R. E., Stroup, S. K. and Henriksson, D. (1978) Fed. Proc. FASEB 37, 1797.

[6] Carter, N., Jeffery, S., Shiels, A., Edwards, Y., Tipler, T. and Hopkinson, D. A. (1979) Biochem. Genet. 17, $837-854$.

[7] Kishida, K. and Ochi, N. (1980) Experientia 36, 42.

[8] Maren, T. H., Ellison, A. C., Pellner, S. K. and Graham, W. B. (1966) Mol. Pharmacol. 2, 144-157.

[9] Pihar, O. (1965) Biochim. Biophys. Acta 104, 608-611.

[10] King, R. W., Garg, L., Huckson, J. and Maren, T. H. (1974) Mol. Pharmacol. 10, 335-343.

[11] Garg, L. (1974) J. Pharmacol. Exp. Therap. 189, $557-562$.

[12] Osborne, W. R. A. and Tashian, R. E. (1975) Anal. Biochem. 64, 297-303.

[13] Kageoka, T., Hewett-Emmett, D., Stroup, S. K., Yu, Y.-S. L. and Tashian, R. E. (1981) Biochem. Genet. in press.

[14] Laemmli, U. K. and Favre, M. (1973) J. Mol. Biol. 80, 575.

[15] Henriksson, D., Tanis, R. J. and Tashian, R. E. (1980) Biochem. Biophys. Res. Commun. 96, 135-142.

[16] Koester, M. K., Register, A. M. and Noltmann, E. A. (1977) Biochem. Biophys. Res. Commun. 76, 196-204.

[17] Holmes, R. S. (1976) J. Exp. Zool. 197, 289-295.

[18] Hewett-Emmett, D. and Tashian, R. E. (1979) Am. J. Human Genet. 31, 50A.

[19] Hewett-Emmett, D. and Tashian, R. L. (1981) Am. J. Phys. Anthropol. 54, 232-233.

[20] Jeffery, S., Edwards, Y. and Carter, N. (1980) Biochem. Genet. 18, 843-849.

[21] Carter, N. D. et al. (1981) unpublished.

[22] Garg, L. (1975) J. Pharmacol. Exp. Therap. 192, $297-302$.

[23] Weatherall, D. J. and Clegg, J. B. (1979) Cell 16, $467-479$.

[24] Bardin, C. W. and Catterall, J. F. (1981) Science 211, 1285-1294.

[25] Dodgson, S. J., Forster, R. E., Storcy, B. T. and Mela, L. (1980) Proc. Natl. Acad. Sci. USA 77, 5562-5566.

[26] Jabusch, J. R., Bray, R. P. and Deutsch, H. F. (1980) J. Biol. Chem. 255, 9196-9204.

[27] Ferrell, R. E., Stroup, S. K., Tanis, R. J. and Tashian, R. E. (1978) Biochim. Biophys. Acta 533, 1-11. 